\title{
SOCIETY FOR COMPUTERS IN PSYCHOLOGY Editorial
}

This issue of Behavior Research Methods, Instruments, \& Computers comprises, in part, articles based on presentations at the 32nd Annual Meeting of the Society for Computers in Psychology (SCiP).

\section{The 2002 Annual Meeting}

The one-day conference was held at the Hyatt Regency Crown Center in Kansas City, MO, on November 21,2002 . The program included more than 40 stimulating presentations in a dozen paper and poster sessions. Topics covered a wide range of computer-based research and teaching techniques, including Internet applications for both teaching and research, research tools, statistical applications, and methodology. The program chair for the 2002 meeting was Robert Proctor, assisted by Roman Taraban and Kim Vu.

David Washburn delivered the Presidential Address, "The Games Psychologists Play (and the Data They Provide)." William Uttal presented an invited overview of recent developments in neuroscience techniques, "Cognitive Imaging: A New Phrenology?" In another invited address, Robert Glushko presented his vision of electronic document evolution, "The Document Strikes Back."

A complete listing of titles, authors, and abstracts for papers presented at the SCiP conference is available at the SCiP Web page: http://www.scip.ws.

The John Castellan Student Paper Award for 2002 recognizes the work of Andrew Edmonds of Clemson University, reported here in his paper, "Uzilla: A New Tool for Web Usability Testing."

The SCiP articles that are included in this issue were contributed to BRMIC and reviewed by the journal's consulting editors, members of the program committee of the SCiP conference, and ad hoc reviewers who have expertise in each paper's area. My thanks to all who contributed in this way to the quality of the papers in this issue.

\section{The 2003 Annual Meeting}

The 33rd Annual Meeting of SCiP will be held at the Hyatt Regency Hotel, Vancouver, British Columbia, on Thursday, November 6, 2003, just before the annual meeting of the Psychonomic Society. The Call for Papers may be found elsewhere in this issue and at www.scip.ws. Presentations geared for all levels are appropriate, including introductory tutorials, new ways of teaching or collecting data, and technical information for researchers and programmers. Individuals interested in suggesting a topic for a symposium or submitting a paper for the 2003 meeting are urged to contact the program chair, Roman Taraban, with questions or comments.

Roman Taraban

SCiP Program Chair

Department of Psychology

Texas Tech University

Lubbock, TX 79409-2051

E-mail: roman.taraban@ttu.edu

Phone: (806) 742-3711 ext. 247

\begin{abstract}
About the Society for Computers in Psychology
Membership in SCiP and participation at the meeting are open to all who are interested in the uses of computers in psychological research, teaching, and applications. Information about joining SCiP or participating in its meetings may be obtained from the secretary-treasurer, Katja WiemerHastings, Northern Illinois University (katja@niu.edu). Students are welcome to join the society and participate in its meetings.
\end{abstract}


The president of SCiP for 2003-2004 is Curt Burgess, University of California, Riverside; the past president is David Washburn, Georgia State University; and the president-elect is Robert Proctor, Purdue University. Katja Wiemer-Hastings is secretary-treasurer. The other members of the steering committee are Michael Birnbaum, California State University, Fullerton; Paula Goolkasian, University of North Carolina, Charlotte; John Krantz, Hanover College; Kay Livesay, University of San Francisco; Cyndi McDaniel, Northern Kentucky University; Ken McGraw, University of Mississippi; Ulf Reips, University of Zurich; Larry Rosenblum, University of California, Riverside; and Christopher Wolfe, Miami University. Curt Burgess is webmaster (www.scip.ws).

Jonathan Vaughan

Hamilton College 